ARTICLE

https://doi.org/10.1038/s41467-019-09400-w

\title{
Vanadium disulfide flakes with nanolayered titanium disulfide coating as cathode materials in lithium-ion batteries
}

Lu Li', Zhaodong Li (iD ${ }^{2}$, Anthony Yoshimura ${ }^{2}$, Congli Sun ${ }^{3}$, Tianmeng Wang ${ }^{4}$, Yanwen Chen ${ }^{4}$, Zhizhong Chen ${ }^{5}$, Aaron Littlejohn², Yu Xiang ${ }^{2}$, Prateek Hundekar', Stephen F. Bartolucci6, Jian Shi (0) ${ }^{5}$, Su-Fei Shi (i) 4,7, Vincent Meunier ${ }^{2,5}$, Gwo-Ching Wang (10 ${ }^{2}$ \& Nikhil Koratkar ${ }^{1,5}$

Unlike the vast majority of transition metal dichalcogenides which are semiconductors, vanadium disulfide is metallic and conductive. This makes it particularly promising as an electrode material in lithium-ion batteries. However, vanadium disulfide exhibits poor stability due to large Peierls distortion during cycling. Here we report that vanadium disulfide flakes can be rendered stable in the electrochemical environment of a lithium-ion battery by conformally coating them with a $2.5 \mathrm{~nm}$ thick titanium disulfide layer. Density functional theory calculations indicate that the titanium disulfide coating is far less susceptible to Peierls distortion during the lithiation-delithiation process, enabling it to stabilize the underlying vanadium disulfide material. The titanium disulfide coated vanadium disulfide cathode exhibits an operating voltage of $\sim 2 \mathrm{~V}$, high specific capacity $\left(\sim 180 \mathrm{mAh} \mathrm{g}^{-1} @ 200 \mathrm{~mA} \mathrm{~g}^{-1}\right.$ current density) and rate capability $\left(\sim 70 \mathrm{mAh} \mathrm{g}^{-1} @ 1000 \mathrm{~mA} \mathrm{~g}^{-1}\right)$, while achieving capacity retention close to $100 \%$ after 400 charge-discharge steps.

\footnotetext{
${ }^{1}$ Department of Mechanical, Aerospace and Nuclear Engineering, Rensselaer Polytechnic Institute, 110 8th Street, Troy, NY 12180, USA. ${ }^{2}$ Department of Physics, Applied Physics, and Astronomy, Rensselaer Polytechnic Institute, 110 8th Street, Troy, NY 12180, USA. ${ }^{3}$ Department of Materials Science and Engineering, University of Wisconsin-Madison, 1509 University Ave, Madison, WI 53706, USA. ${ }^{4}$ Department of Chemical and Biological Engineering, Rensselaer Polytechnic Institute, 110 8th Street, Troy, NY 12180, USA. ${ }^{5}$ Department of Materials Science and Engineering, Rensselaer Polytechnic Institute, 110 8th Street, Troy, NY 12180, USA. ${ }^{6}$ U.S. Army Combat Capabilities Development Command Armaments Center, Watervliet Arsenal, NY 12189, USA. ${ }^{7}$ Department of Electrical, Computer and Systems Engineering, Rensselaer Polytechnic Institute, 110 8th Street, Troy, NY 12180, USA. These authors contributed equally: Lu Li, Zhaodong Li. Correspondence and requests for materials should be addressed to N.K. (email: koratn@rpi.edu)
} 


\section{T} ransition metal dichalcogenides (TMDs) are an emerging class of two-dimensional (2D) materials with chemical formula of $\mathrm{MX}_{2}$, where $\mathrm{M}$ denotes a transition metal (e.g., $\mathrm{Mo}, \mathrm{W}, \mathrm{Re}$, etc.) and $\mathrm{X}$ represents a chalcogen (e.g., $\mathrm{S}$ or Se) $)^{1,2}$. Recently there has been intense research activity directed towards deploying TMD materials for electrochemical energy storage applications ${ }^{3-5}$. However most of the commonly used TMDs such as molybdenum disulfide $\left(\mathrm{MoS}_{2}\right)$ and tungsten disulfide $\left(\mathrm{WS}_{2}\right)$ are semiconductors with low electrical conductivity, which limits their usefulness as battery materials. Deployment of such TMDs as electrodes is only possible when they are mixed with highly conductive carbon-based materials. However, this greatly reduces the active material loading and limits the high-rate capability of the electrode.

In contrast, vanadium disulfide $\left(\mathrm{VS}_{2}\right)$ is a conducting TMD material ${ }^{6}$ and exhibits metallic behavior (Supplementary Fig. 1). Therefore, $\mathrm{VS}_{2}$-based electrodes could in principle be deployed in lithium (Li)-ion batteries without requiring a high content of conductive carbon additives or conductive binders, which are inactive materials. In spite of this promise, the realization of $\mathrm{VS}_{2}-$ based electrodes ${ }^{7-11}$ in Li-ion batteries has been limited by its poor stability, which leads to low cycle life. In the literature, volume expansion leading to pulverization ${ }^{7}$ is cited as a reason for poor stability of $\mathrm{VS}_{2}$ in Li-ion batteries. To buffer the volume expansion, $\mathrm{VS}_{2}$ is mixed with mechanically resilient carbon materials (e.g. graphene) to create a composite electrode that offers improved stability ${ }^{7}$

Here, we demonstrate that $\mathrm{VS}_{2}$ flakes can be stabilized in the electrochemical environment of a Li-ion battery by simply coating them with a few nm thick layer of titanium disulfide $\left(\mathrm{TiS}_{2}\right)$. In our approach, densely packed $\mathrm{VS}_{2}$ flakes with high crystallinity are grown directly on the surface of a carbon nanotube current collector substrate by chemical vapor deposition (CVD). Then a conformal $\mathrm{TiS}_{2}$ coating is deposited on the $\mathrm{VS}_{2}$ platelets by atomic layer deposition (ALD). Electrochemical testing as well as in situ optical as well as ex situ scanning electron microscopy (SEM) observation reveal a pronounced stability enhancement for the $\mathrm{TiS}_{2}$-coated $\mathrm{VS}_{2}$ as compared to bare $\mathrm{VS}_{2}$. First-principles density functional theory (DFT) calculations indicate that unlike $\mathrm{VS}_{2}$ which undergoes large Peierls distortion during lithiation/ delithiation, the $\mathrm{TiS}_{2}$ lattice remains relatively undisturbed. Consequently, the $\mathrm{TiS}_{2}$ coating provides an electrochemically and mechanically stable support that "buttresses" the $\mathrm{VS}_{2}$ platelets and prevents the underlying $\mathrm{VS}_{2}$ sheets from delaminating and peeling off the surface. To our knowledge, the role of Peierls distortion (during lithiation/delithiation) in promoting the failure of $\mathrm{VS}_{2}$ electrodes has not been identified in the past, and thus constitutes a key contribution of this work. The resultant $\mathrm{VS}_{2}-$ $\mathrm{TiS}_{2}$ structures are remarkably resilient and offer a striking enhancement in stability over the baseline $\mathrm{VS}_{2}$ electrode in Li-ion batteries. In fact, the performance of the $\mathrm{TiS}_{2}$ protective coating is superior to ALD deposited layers of metal oxides (e.g. $\mathrm{Al}_{2} \mathrm{O}_{3}$, $\left.\mathrm{ZrO}_{2}, \mathrm{TiO}_{2}\right)^{12}$, fluorides $\left(\text { e.g. } \mathrm{AlF}_{3}\right)^{13}$, and nitrides (e.g. TiN $)^{14}$ that have been used to passivate different electrode surfaces. Deposition of such condensed and electrically insulating films induces low Li-ion diffusivity and electron transport, and thus suppresses initial capacity and rate capability ${ }^{15}$. In fact, such capacity quelling effects have been reported even for extremely thin (few angstroms thick) ALD deposited coatings. The $\mathrm{TiS}_{2}$ coating on the other hand does not suppress the specific capacity or the rate capability of $\mathrm{VS}_{2}$. This we presume is because $\mathrm{TiS}_{2}$ is also a TMD material and is compatible with $\mathrm{VS}_{2}$. Moreover, $\mathrm{TiS}_{2}$ is conductive and shares a similar electronic structure (Supplementary Fig. 1) as $\mathrm{VS}_{2}$, which allows the high-rate capability performance of $\mathrm{VS}_{2}$ to be retained despite being sandwiched by $\mathrm{TiS}_{2}$ layers.

\section{Results}

Synthesis and characterization. A densely packed forest of $\mathrm{VS}_{2}$ sheets was grown (Methods) on a carbon nanotube current collector substrate (Supplementary Fig. 2) by a dual-zone atmospheric pressure chemical vapor deposition (APCVD) process (schematically represented in Fig. 1a). Since metal halide precursors $^{16}$ tend to offer better growth regulation and reproducibility when compared to metal oxides, we have selected the chloride reactant $\left(\mathrm{VCl}_{3}\right)$ and $\mathrm{S}$ powder as precursors for CVD growth. In addition, $\sim 5 \% \mathrm{H}_{2}$ was incorporated into the carrier gas in the CVD reactor in order to generate more active species (e.g., $\mathrm{VCl}^{-}, \mathrm{VCl}_{2}^{-}$) from the vanadium precursor molecules. This enhances the nucleation site density and growth rate of the $\mathrm{VS}_{2}$ flakes. A carbon nanotube (CNT) film was selected as the current collector substrate because of its light weight, high conductivity and flexibility. The $\mathrm{VS}_{2}$ platelets are observed predominantly on the surface of the CNT film. An examination of the junction (Supplementary Fig. 3) between the $\mathrm{VS}_{2}$ and CNT substrate indicates that the $\mathrm{VS}_{2}$ platelets are embedded (or lodged) into the CNT current collector. This is important since it indicates a strong interface and good electrical connectivity between the $\mathrm{VS}_{2}$ flakes and the CNT current collector substrate.

After the $\mathrm{VS}_{2}$ growth was completed, ALD was used to deposit a nanolayered $\mathrm{TiS}_{2}$ coating over the $\mathrm{VS}_{2}$ platelets $\left(\mathrm{VS}_{2}-\mathrm{TiS}_{2}\right)$ by using $\mathrm{TiCl}_{4}$ and $\mathrm{S}$ as precursors (Methods). The morphologies of the as-synthesized $\mathrm{VS}_{2}$ and $\mathrm{VS}_{2}-\mathrm{TiS}_{2}$ structures are revealed by top-view SEM imaging as shown in Fig. 1b-e. In Fig. 1b, densely packed micrometer scale $\mathrm{VS}_{2}$ flakes can be seen growing vertically off the current collector. The smooth flakes of regular hexagon or semi-hexagon shape (Fig. 1c) suggest their high crystallinity. The ALD-deposited $\mathrm{TiS}_{2}$ faithfully replicates the nanoforest structure and flake shape of the $\mathrm{VS}_{2}$ due to the excellent conformability and precise thickness control of the ALD technique (Fig. 1d). Note that there is a roughening (Fig. 1e) of the $\mathrm{VS}_{2}$ flakes post $\mathrm{TiS}_{2}$ deposition which is attributed to the polycrystalline phase of ALD $\mathrm{TiS}_{2}$. The elemental distribution results obtained by EDS elemental mapping (Supplementary Figs. 4-5) further confirm the homogeneous distribution of $\mathrm{V}, \mathrm{S}$ and $\mathrm{V}, \mathrm{S}, \mathrm{Ti}$ atoms on the surfaces of $\mathrm{VS}_{2}$ and the $\mathrm{VS}_{2}-\mathrm{TiS}_{2}$ structures, respectively. X-ray photoelectron spectroscopy (XPS) also provided confirmation of the $\mathrm{VS}_{2}$ and $\mathrm{TiS}_{2}$ phase (Supplementary Fig. 6).

To evaluate the electrical conductivity of the $\mathrm{VS}_{2}$ and $\mathrm{VS}_{2}-\mathrm{TiS}_{2}$ flakes, electrical transport measurements were performed on individual flakes (Supplementary Fig. 7). Due to the twodimensional morphology of the flakes, the sheet resistance ${ }^{17}$ was used to compare the conductivity of the $\mathrm{VS}_{2}$ and $\mathrm{VS}_{2}-\mathrm{TiS}_{2}$ flakes. The sheet resistance $\left(R_{\mathrm{s}}\right)$ of the $\mathrm{VS}_{2}$ flake is in the 200-900 $\Omega \square^{-1}$ range, while that of the $\mathrm{VS}_{2}-\mathrm{TiS}_{2}$ flake lies in the 500-2400 $\Omega \square^{-1}$ range. After $\mathrm{TiS}_{2}$ deposition, the conductivity of the $\mathrm{VS}_{2}$ flake has decreased, but is still comparable to pure $\mathrm{VS}_{2}$. These results indicate that the intrinsic high electrical conductivity of $\mathrm{VS}_{2}$ is retained in the $\mathrm{VS}_{2}-\mathrm{TiS}_{2}$ architecture.

The $\mathrm{VS}_{2}$ and $\mathrm{VS}_{2}-\mathrm{TiS}_{2}$ flakes were further characterized by Raman spectroscopy (Fig. 1f). We observe Raman peaks of $\mathrm{VS}_{2}$ at 263, 304, and $379 \mathrm{~cm}^{-1}$. The peaks at 263 and $379 \mathrm{~cm}^{-1}$ correspond to the $E_{1 \mathrm{~g}}$ and $A_{1 \mathrm{~g}}$ modes of $\mathrm{VS}_{2}$ and are comparable to previous reports ${ }^{16,18}$ for CVD grown $\mathrm{VS}_{2}$. In our experiments, we also observed an additional peak at $304 \mathrm{~cm}^{-1}$, which we attribute to an in-plane sliding mode $\left(E^{\prime}\right)$ for $\mathrm{VS}_{2}$ that can arise due to interlayer mismatch ${ }^{19}$. ALD coating of $\mathrm{TiS}_{2}$ on $\mathrm{VS}_{2}$ introduced a new peak at $324 \mathrm{~cm}^{-1}$ which corresponds ${ }^{20-22}$ to the $A_{1 \mathrm{~g}}$ mode of $\mathrm{TiS}_{2}$. Other peaks exhibit similar position and width indicating that the $\mathrm{VS}_{2}$ structure was well preserved after the ALD process. X-ray diffraction (XRD) analysis also confirmed the crystallinity of the as-grown $\mathrm{VS}_{2}$ and $\mathrm{VS}_{2}-\mathrm{TiS}_{2}$ flakes (Fig. 1g). It should be noted that in the literature ${ }^{7,16,18,23-27}$ there is large 

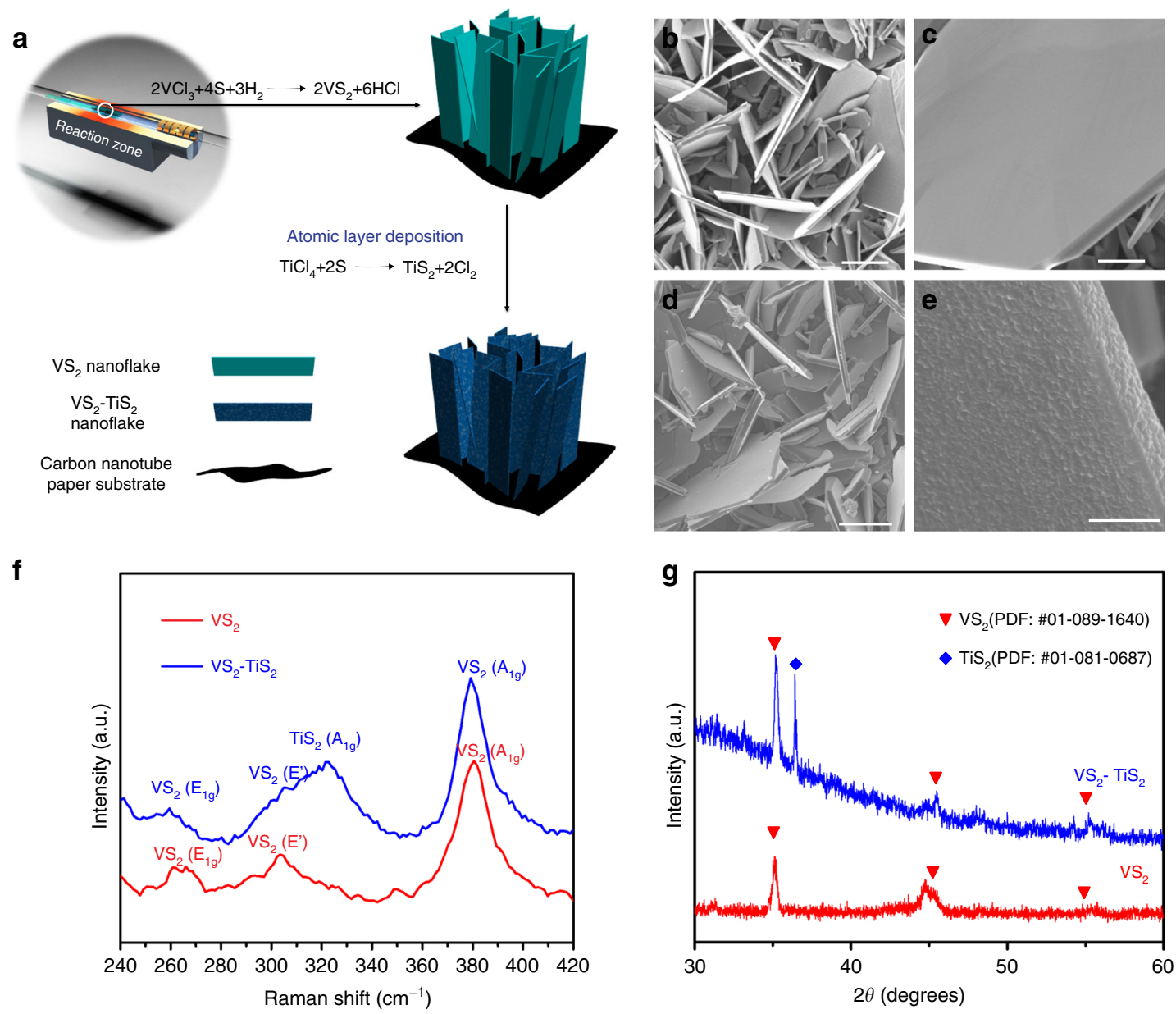

Fig. 1 Synthesis and characterization of $\mathrm{VS}_{2}$ and $\mathrm{VS}_{2}-\mathrm{TiS}_{2}$ flakes. a Schematic of the procedure for fabricating $\mathrm{VS}_{2}$ and $\mathrm{VS}_{2}-\mathrm{TiS}_{2}$ composites. b, c Top-view SEM (b: scale bar $=10 \mu \mathrm{m}$; c: scale bar $=3 \mu \mathrm{m})$ of $V S_{2}$ flakes with different magnification. $\mathbf{d}$, e Top-view SEM (d: scale bar $=10 \mu \mathrm{m}$; e: scale bar $\left.=1 \mu \mathrm{m}\right)$ of the $\mathrm{VS}_{2}-\mathrm{TiS}_{2}$ structures with different magnification. $\mathbf{f}$ Raman spectrum of $\mathrm{VS}_{2}$ and $\mathrm{VS}_{2}-\mathrm{TiS}_{2}$. $\mathbf{g} \mathrm{X}$-ray diffraction pattern of $\mathrm{VS}_{2}$ and $V S_{2}-\mathrm{TiS}_{2}$ flakes

scatter in the Raman data for $\mathrm{VS}_{2}$. This is illustrated in Supplementary Table 1. These differences arise due to the growth method (i.e., CVD vs. hydrothermal synthesis), laser (polarization) set-up, flake curvature as well as poor environmental stability when $\mathrm{VS}_{2}$ Raman measurements are taken under atmospheric conditions (Supplementary Fig. 8). These effects are discussed in detail in the Supplementary Information. Raman spectra of the CNT substrate before and after the depositions are provided in Supplementary Fig. 9. The G band at $\sim 1580 \mathrm{~cm}^{-1}$ is attributed to vibration of $\mathrm{sp}^{2}$ bonded carbon atoms in the CNT, while the D-band $\left(\sim 1350 \mathrm{~cm}^{-1}\right)$ is attributed to defects and disorder in the $\mathrm{CNT}^{28}$. The ratio of the intensity of the $\mathrm{D}$ to $\mathrm{G}$ band $\left(I_{\mathrm{D}} / I_{\mathrm{G}}\right)$ of the pristine CNT film is $\sim 0.45$. This value is increased to $\sim 0.6$ after deposition. This slight increase in CNT defectiveness is presumably due to the high temperature and aggressive chemical environment related to the use of halogen precursors. There is also a higher frequency shoulder to the $\mathrm{G}$ band ( $\mathrm{D}^{\prime}$ band $\sim 1620 \mathrm{~cm}^{-1}$ ); this shoulder becomes more prominent after deposition. Also, a new peak at $\sim 1438 \mathrm{~cm}^{-1}$ appeared post deposition, which is related to other carbonaceous materials $^{29}$

Transmission electron microscopy (TEM) was performed to probe the structure of the synthesized $\mathrm{VS}_{2}$ and $\mathrm{VS}_{2}-\mathrm{TiS}_{2}$ flakes. The flake edges appear to be roughened (Fig. 2a, c) after the $\mathrm{TiS}_{2}$ ALD deposition, which is consistent with the SEM observations in Fig. 1e. High-resolution TEM (HRTEM) imaging of $\mathrm{VS}_{2}$ is shown in Fig. 2b. The inset of Fig. $2 b$ shows the corresponding fast Fourier transform (FFT) pattern. The well-defined spots in the FFT pattern indicates the single-crystal structure of the $\mathrm{VS}_{2}$ sheet planes viewed along the [010] zone axis. Some visible spots in the FFT are labeled as (102), $(\overline{10} \overline{2}),(002),(00 \overline{2}),(100)$, and $(\overline{100})$. The measured reciprocal spacing $G(100)_{\text {measured }}=2.24 \AA^{-1}$ using the calibration scale bar matches well with the calculated theoretical $G(100)_{\text {theoretical }}=2.25 \AA^{-1}$. The real space spacing $d_{100}=(\sqrt{3} / 2) a=2 \pi / G(100)$, where $a$ is the lattice constant. The extracted value of $a \approx 3.24 \AA$ is consistent with the bulk lattice constant (3.221 $\AA$ ) of $\mathrm{VS}_{2}$ (PDF: \#01-089-1640). It is noted that weaker spots about $10^{\circ}$ next to the $(102)$ and $(\overline{1} 0 \overline{2})$ spots were observed in the FFT pattern. This is likely due to the rotation of the stacked multilayer $\mathrm{VS}_{2}$ structure during growth. Figure $2 \mathrm{~d}$ shows HRTEM imaging of a $\mathrm{VS}_{2}-\mathrm{TiS}_{2}$ flake. ALD of $\mathrm{TiS}_{2}$ introduced a $\sim 2.5$-nm-thick layer on the surface. The inset in Fig. $2 \mathrm{~d}$ is the FFT pattern from a selected region indicated by the green dashed box in the HRTEM image. Many spots from $\mathrm{VS}_{2}$ still can be identified, for example, (100), (010), (110) and (003), but there are more spots in ring-like contrast that is consistent with polycrystalline $\mathrm{TiS}_{2}$. FFT of other $\mathrm{VS}_{2}-\mathrm{TiS}_{2}$ flakes were analyzed and similar results were obtained. These confirm the existence of the $\mathrm{TiS}_{2}$ polycrystalline phase.

Electrochemical properties. To evaluate the electrochemical performance of the $\mathrm{VS}_{2}$ and $\mathrm{VS}_{2}-\mathrm{TiS}_{2}$ electrodes, coin cells were assembled (Methods). The galvanostatic charge-discharge voltage 

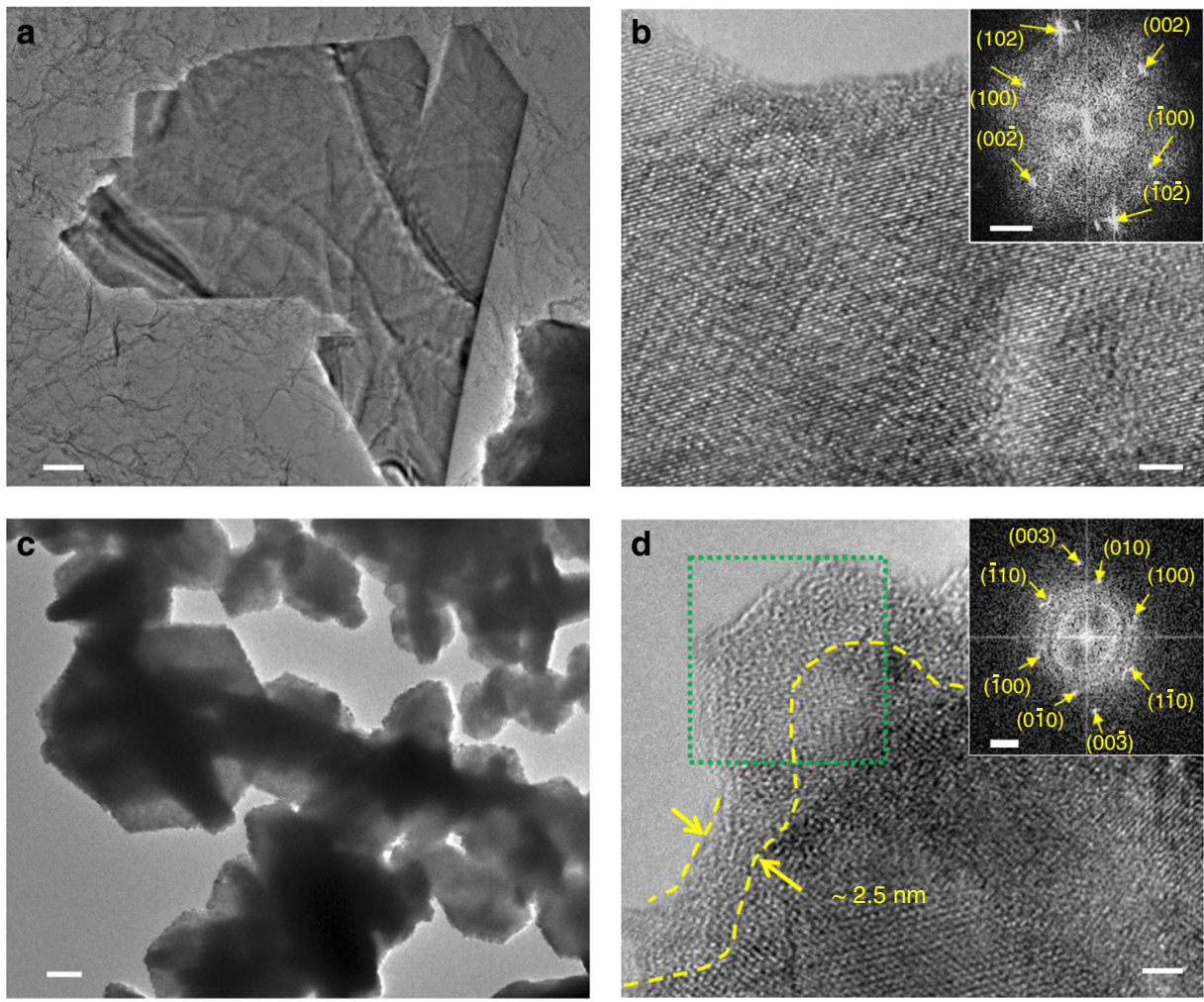

Fig. 2 TEM and HRTEM characterization of $V S_{2}$ and $V S_{2}-T i S_{2}$. a TEM (scale bar $=200 \mathrm{~nm}$ ) and $\mathbf{b}$ HRTEM image (scale bar $=2 \mathrm{~nm}$, inset shows the corresponding FFT pattern (scale bar $=2 \mathrm{~nm}^{-1}$ )) of a typical VS flake. c TEM (scale bar $=200 \mathrm{~nm}$ ) and $\mathbf{d}$ HRTEM image (scale bar $=2 \mathrm{~nm}$, inset shows the FFT pattern (scale bar $=2 \mathrm{~nm}^{-1}$ ) of the region within the green box) of a typical VS 2 -TiS ${ }_{2}$ flake. TEM transmission electron microscopy, HRTEM highresolution transmission electron microscopy, FFT Fast Fourier Transform

profiles of the $\mathrm{VS}_{2}$ and $\mathrm{VS}_{2}-\mathrm{TiS}_{2}$ electrodes between 1.5 and $3.5 \mathrm{~V}$ (vs. $\mathrm{Li} / \mathrm{Li}^{+}$) at a current density of $\sim 200 \mathrm{~mA} \mathrm{~g}^{-1}$ are shown in Fig. 3a. The electrochemical intercalation and removal of $\mathrm{Li}$ in $\mathrm{VS}_{2}$ can be described by the following reaction: $x \mathrm{Li}^{+}+x e^{-}+\mathrm{VS}_{2} \leftrightarrow \mathrm{Li}_{x} \mathrm{VS}_{2}$. The voltage plateau in the discharge/charge curve at about $2 \mathrm{~V}$ is indicative of the transition from the $\alpha-\mathrm{VS}_{2}$ to the $\beta-\mathrm{Li}_{x} \mathrm{VS}_{2}$ phase ${ }^{7}$. The lithiated $\mathrm{Li}_{x} \mathrm{VS}_{2}$ phase shows promise as a cathode material in $\mathrm{Li}$-ion batteries. It is noteworthy that the $\mathrm{TiS}_{2}$ surface coating does not suppress the specific capacity of $\mathrm{VS}_{2}$. As Fig. 3a indicates both the bare $\mathrm{VS}_{2}$ and the $\mathrm{VS}_{2}-\mathrm{TiS}_{2}$ core-shell electrode delivers a similar initial (i.e. first cycle) specific capacity of about $180 \mathrm{~mA} \mathrm{~h} \mathrm{~g}$. For the $\mathrm{VS}_{2}$ electrode, the mean operating voltage is at $\sim 2.3 \mathrm{~V}$. After $\mathrm{TiS}_{2}$ coating, the operating voltage of the $\mathrm{VS}_{2}-\mathrm{TiS}_{2}$ electrode dropped to $\sim 2.1 \mathrm{~V}$. One reason for this might be the lattice stress caused by $\mathrm{TiS}_{2}$ growth on the surface of the $\mathrm{VS}_{2}$ flake, which may affect the intercalation and de-intercalation potential of lithium ions into $\mathrm{VS}_{2}$. Moreover, it has been commonly observed that ALD-coated layers affect lithium diffusion and electron transport processes $^{12,30}$, which could also influence the charge-discharge voltage profiles.

The rate performances of the $\mathrm{VS}_{2}$ and $\mathrm{VS}_{2}-\mathrm{TiS}_{2}$ electrodes was investigated as shown in Fig. 3b. Since $\mathrm{TiS}_{2}$ is metallic (Supplementary Fig. 1) similar to $\mathrm{VS}_{2}$, the conductivity of $\mathrm{VS}_{2}$ $\mathrm{TiS}_{2}$ is still comparable to that of pure $\mathrm{VS}_{2}$ (Supplementary Fig. 7). Consequently, the overall rate performance of the $\mathrm{VS}_{2}$ electrode was not significantly affected by the $\mathrm{TiS}_{2}$ coating. The results show that the baseline $\mathrm{VS}_{2}$ and the $\mathrm{VS}_{2}-\mathrm{TiS}_{2}$ electrode exhibits a capacity above 150 and $180 \mathrm{~mA} \mathrm{~h} \mathrm{~g}^{-1}$, respectively in the first five cycles at a current density of $\sim 200 \mathrm{~mA} \mathrm{~g}^{-1}$. Even when the current density is increased to $\sim 2000 \mathrm{~mA} \mathrm{~g}^{-1}(\sim 10 \mathrm{C}$ charge-discharge rate), a specific capacity of $\sim 40 \mathrm{~mA} \mathrm{~h}^{-1}$ is achieved, which indicates that the $\mathrm{VS}_{2}-\mathrm{TiS}_{2}$ electrode is capable of high C-rate operation. The cyclic stability of the samples was investigated at a current density of $\sim 200 \mathrm{~mA} \mathrm{~g}^{-1}$, as shown in Fig. 3c. The $\mathrm{VS}_{2}-\mathrm{TiS}_{2}$ electrode demonstrated excellent cycle stability above $180 \mathrm{~mA} \mathrm{~h} \mathrm{~g}^{-1}$ after 100 charge-discharge steps, while the baseline $\mathrm{VS}_{2}$ electrode under the same conditions exhibits a rapid capacity loss. We also investigated the cycling performance of the electrodes at a higher current density of $\sim 1000 \mathrm{~mA} \mathrm{~g}^{-1}$ (see Fig. 3d). The capacity retention rate is close to $\sim 100 \%$ for the $\mathrm{VS}_{2}-\mathrm{TiS}_{2}$ electrode after 400 continuous cycles of charge and discharge, while the capacity retention of the baseline $\mathrm{VS}_{2}$ electrode was only $\sim 40 \%$ under the same test conditions. The charge and discharge voltage profiles for the $\mathrm{VS}_{2}$ and $\mathrm{VS}_{2}-\mathrm{TiS}_{2}$ electrodes for the 1st, 100th, 200th, 300th and 400th cycles are provided in Supplementary Fig. 10. From the charge-discharge profiles, it is evident that the stability of the electrodes has been significantly improved by the $\mathrm{TiS}_{2}$ coating. Moreover, the overpotential between charge and discharge did not amplify with cycling in the $\mathrm{VS}_{2}-\mathrm{TiS}_{2}$ electrode, which is quite different from the pristine $\mathrm{VS}_{2}$ electrode for which the over-potential continues to increase with cycling.

Figure $3 \mathrm{e}$ compares the $\mathrm{VS}_{2}-\mathrm{TiS}_{2}$ performance with the other cathodes that are commonly used in Li-ion batteries. At low current densities $\left(\sim 200 \mathrm{~mA} \mathrm{~g}^{-1}\right)$, the $\mathrm{VS}_{2}-\mathrm{TiS}_{2}$ electrode provides a very high specific capacity of over $180 \mathrm{~mA} \mathrm{hg}^{-1}$ (after 100 charge-discharge cycles) which is among the best results reported to date. Moreover, unlike many of the other cathode materials, the $\mathrm{VS}_{2}-\mathrm{TiS}_{2}$ electrode can also be operated at high charge-discharge rates and provides a capacity of $\sim 70 \mathrm{~mA} \mathrm{~h} \mathrm{~g}^{-1}$ (after 400 cycles) at a current density of $\sim 1000 \mathrm{~mA} \mathrm{~g}^{-1}$. In the reported literature, only lithium iron phosphate (LFP)-based cathodes provide higher specific capacities at comparable charge 
a

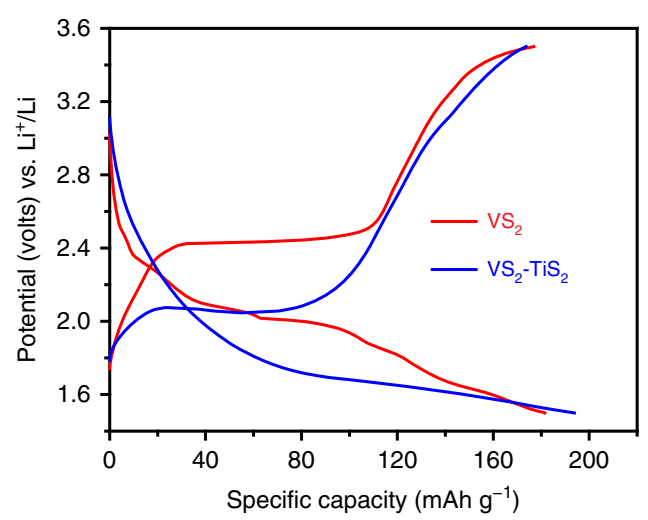

b

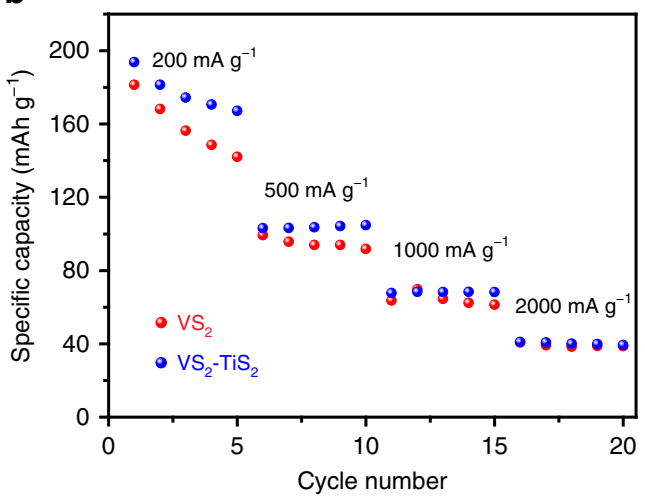

C
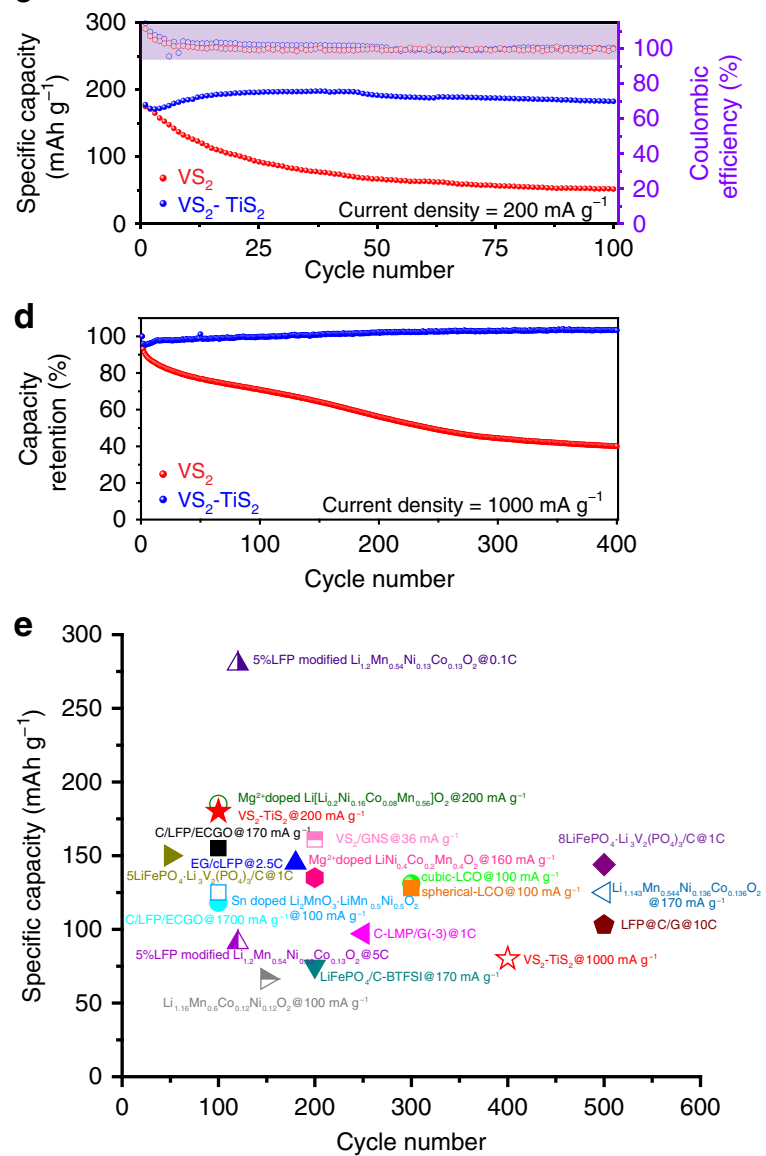

Fig. 3 Electrochemical characterization. a The galvanostatic charge-discharge voltage profiles of the $\mathrm{VS}_{2}$ electrode and $\mathrm{VS}_{2}-\mathrm{TiS}_{2}$ electrode between 1.5 and $3.5 \mathrm{~V}$ (vs. $\mathrm{Li} / \mathrm{Li}^{+}$) at a current density of $200 \mathrm{mAg}^{-1}$. b Rate performance of the $\mathrm{VS}_{2}$ and $\mathrm{VS}_{2}-\mathrm{TiS}_{2}$ electrodes. c Cycling performance and Coulombic efficiency of $\mathrm{VS}_{2}$ electrode and $\mathrm{VS}_{2}-\mathrm{TiS}_{2}$ electrode at $200 \mathrm{mAg}{ }^{-1}$. d Capacity retention of $\mathrm{VS}_{2}$ electrode and $\mathrm{VS}_{2}-\mathrm{TiS}_{2}$ electrode at $1000 \mathrm{mAg} \mathrm{g}^{-1}$. e Comparison of the $\mathrm{VS}_{2}-\mathrm{TiS}_{2}$ electrode (starred) with other commonly used cathodes [7, 37, 38, 39, 40, 41, 42, 43, 44, 45, 46, 47, 48, 49] in Li-ion batteries. The $y$-axis on the plot gives the specific capacity achieved by the cathode material at the completion of a specified number of charge-discharge cycles given on the $x$-axis of the plot. The charge-discharge rate (or current density) at which the electrode is cycled is also specified next to each data point on the plot

- discharge rates. Note that these results are reported for a realistic mass loading $\left(\sim 3.5 \mathrm{mg} \mathrm{cm}^{-2}\right)$ of the $\mathrm{VS}_{2}-\mathrm{TiS}_{2}$ material.

In situ optical characterization. In order to monitor structural changes during lithiation and delithiation, we carried out in situ observation of an individual $\mathrm{VS}_{2}$ and $\mathrm{VS}_{2}-\mathrm{TiS}_{2}$ flake during the charge-discharge process. The schematic of the optical transparent cell is shown in Fig. 4a with the $\mathrm{VS}_{2}$ (or $\mathrm{VS}_{2}-\mathrm{TiS}_{2}$ flake) as the device cathode and Li metal as the anode. The cell was sealed using a transparent glass cover (Supplementary Fig. 11), through which in situ observation of structural changes during lithiation and delithiation could be performed. To better monitor the structure change, we chose relatively thinner flakes of $\sim 20 \mathrm{~nm}$ in thickness (Supplementary Fig. 12). The freshly sealed $\mathrm{VS}_{2}$ or $\mathrm{VS}_{2^{-}}$ $\mathrm{TiS}_{2}$ flake showed an open circuit voltage at around $2.6 \mathrm{~V}$ vs. $\mathrm{Li}$ / $\mathrm{Li}^{+}$. We carried out lithiation by gradually decreasing the cathode potential to $1.5 \mathrm{~V}$ (vs. $\mathrm{Li} / \mathrm{Li}^{+}$). Subsequently, the cathode potential was increased to $3.5 \mathrm{~V}$ (vs. $\mathrm{Li} / \mathrm{Li}^{+}$), to complete the delithiation process. Voltage profiles for the $\mathrm{VS}_{2}$ and $\mathrm{VS}_{2}-\mathrm{TiS}_{2}$ cells are shown in Supplementary Fig. 13. Note that the gap between the electrodes is much larger for the in situ cell as compared to a coin cell, which lead to a higher over-potential (Supplementary Fig. 13).
As shown in Fig. $4 \mathrm{~b}-\mathrm{d}$, for the pure $\mathrm{VS}_{2}$ flake, we observe significant changes in the color and morphology of the flake under the optical microscope. During the lithiation process (Fig. 4c), partial transparency appeared on the original $\mathrm{VS}_{2}$ flake, and this change was not reversible when carrying out the delithiation process. In fact, the transparency spreads over the entire $\mathrm{VS}_{2}$ flake, indicating significant permanent (irreversible) change or damage to the flake. In stark contrast to this, with the $\mathrm{TiS}_{2}$ coating, there is no obvious color or structural change to the $\mathrm{VS}_{2}-\mathrm{TiS}_{2}$ flake as shown in Fig. $4 \mathrm{e}-\mathrm{g}$. The reflection light intensity contrast, which is the reflection from the $2 \mathrm{D}$ flake compared with that from the substrate, is related to the absorption of the 2D flake. The observed transparency spreading can thus be understood as a decrease in the overall absorption of the $\mathrm{VS}_{2}$ flake. Since uncoated $\mathrm{VS}_{2}$ is not stable during lithium intercalation, it likely undergoes delamination, which effectively decreases the overall absorption and hence induces the observed transparency. This interpretation is confirmed by the completely different behavior of $\mathrm{TiS}_{2}$-coated $\mathrm{VS}_{2}$. The $\mathrm{TiS}_{2}$-coated $\mathrm{VS}_{2}$ is stable during the lithium intercalation process and we expect the thickness of the $\mathrm{VS}_{2}$ flake remains unchanged. The reflection contrast of the $\mathrm{TiS}_{2}$-coated $\mathrm{VS}_{2}$ flake, therefore, remains unchanged during and after the lithium intercalation, consistent with our observation. 


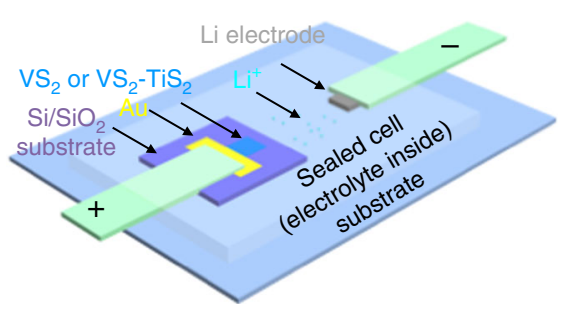

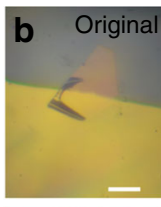
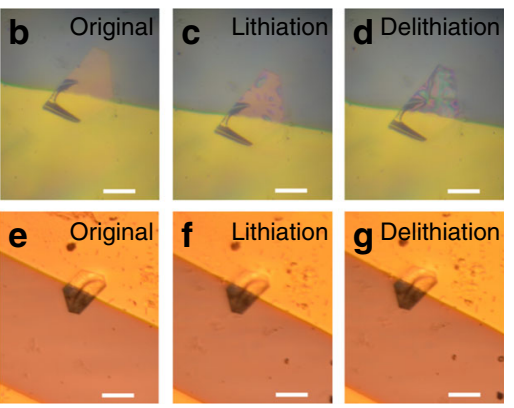
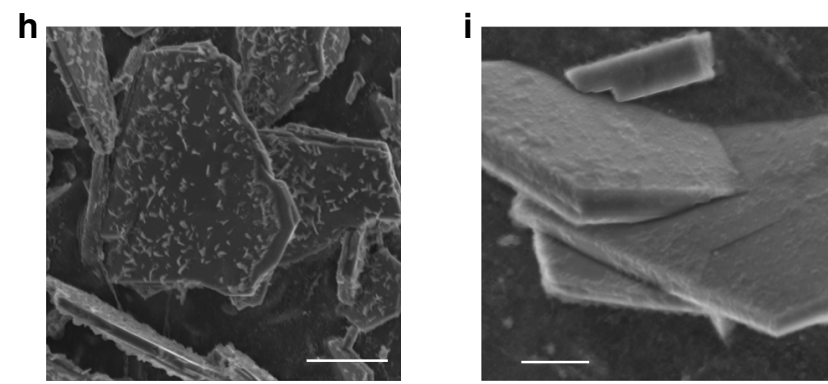

Fig. 4 Observations of structural changes to the $\mathrm{VS}_{2}$ and $\mathrm{VS}_{2}-\mathrm{TiS}_{2}$ flakes during the lithiation and delithiation process. a Schematic of transparent cell set-up for in situ optical imaging. $\mathbf{b}-\mathbf{d}$ Optical images of $V S_{2}$ flake at the original status, lithiation status, and delithiation status. Scale bar $=20 \mu \mathrm{m}$. $\mathbf{e}-\mathbf{g}$ Optical images of $\mathrm{VS}_{2}-\mathrm{TiS}_{2}$ flake at the original status, lithiation status, and delithiation status. Scale bar $=20 \mu \mathrm{m}$. The color difference of the background shown in $(\mathbf{b}-\mathbf{d})$ and $(\mathbf{e}-\mathbf{g})$ was caused by using a different light source of the optical microscope. $\mathbf{h}$ Ex situ SEM image (scale bar $=10 \mu \mathrm{m})$ of $\mathrm{VS}_{2}$ flakes after galvanostatic charge-discharge cycling at $1000 \mathrm{~mA} \mathrm{~g}^{-1}$ for 400 cycles. $\mathbf{i}$ Corresponding SEM image (scale bar $\left.=3 \mu \mathrm{m}\right)$ of VS $\mathrm{STiS}_{2}$ flakes after galvanostatic charge-discharge cycling at $1000 \mathrm{~mA} \mathrm{~g}^{-1}$ for 400 cycles. SEM scanning electron microscopy

Ex situ SEM characterization. These results were also corroborated by ex situ SEM imaging of the flakes. For this, we opened the coin cells (tested in Fig. 3d) that were cycled for 400 charge - discharge steps inside a glove box. The $\mathrm{VS}_{2}$ and $\mathrm{VS}_{2}-\mathrm{TiS}_{2}$ electrodes were extracted from the coin cells, and SEM was used to observe the morphology of these electrodes. As shown in Fig. 4i, no obvious change in the morphology can be observed for the $\mathrm{VS}_{2}-\mathrm{TiS}_{2}$ electrode. These observations are consistent with the in situ optical imaging and indicate that with the help of the $\mathrm{TiS}_{2}$ coating, the structural integrity of the $\mathrm{VS}_{2}$ could be maintained during electrochemical cycling. In contrast, SEM imaging of the bare $\mathrm{VS}_{2}$ electrode revealed a multitude of $\mathrm{VS}_{2}$ flakes delaminating and peeling off (see Fig. 4h) the surface of the electrode, confirming structural damage during cycling, which is responsible for the fast capacity fade.

First principles calculations. Density functional theory calculations were carried out (Methods) to obtain a fundamental understanding of lithiation/delithiation in and out of the $\mathrm{VS}_{2}$ and $\mathrm{VS}_{2}-\mathrm{TiS}_{2}$ structures. The calculations are not for a single sheet, rather all calculations assumed a bulk structure. That is, the outof-plane lattice constants were chosen so that it minimized the free energy of bulk $\mathrm{Li}_{2} \mathrm{VS}_{2}$ and bulk $\mathrm{Li}_{2} \mathrm{TiS}_{2}$. The dynamics of an individual Li-ion can be described as a series of migrations between adjacent transition metal sites belonging to the same $\mathrm{MS}_{2}$ $(\mathrm{M}=\mathrm{V}$ or $\mathrm{Ti}$ ) layer. Each of these migrations requires that an adjacent Li site be vacant. It therefore follows that the migration of a Li-ion is also the migration of a vacancy in the opposite direction. To model these migrations, we remove a Li-ion from a fully intercalated system, leaving behind a single Li vacancy. We then use the climbing-image nudged elastic band method (CNEB) to calculate the energy barrier associated with moving a Li-ion from an adjacent site into that vacancy. Figure 5e compares the energy profiles of these migration processes in $\mathrm{VS}_{2}$ and $\mathrm{TiS}_{2}$. Clearly, $\mathrm{VS}_{2}$ is associated with a much larger energy barrier for migration. This is because $\mathrm{VS}_{2}$ and $\mathrm{TiS}_{2}$ respond very differently to the presence of a Li vacancy. Specifically, $\mathrm{VS}_{2}$ layers "Peierls distort" when a vacancy is introduced, so that the $\mathrm{V}$ atoms are alternatingly pinched and pulled apart (Fig. $5 \mathrm{a}, \mathrm{c}$ ). When a $\mathrm{Li}$ migrates, the $\mathrm{VS}_{2}$ distortion must reverse its phase, i.e., the pinched atoms separate, while the pulled atoms converge. This rearrangement has an energy cost which is reflected in $\mathrm{VS}_{2}$ 's tall energy profile (Fig. 5e). Meanwhile, the fully intercalated $\mathrm{TiS}_{2}$ crystal is much less susceptible to distortion, in that we see very little deviation from the pristine structure when a vacancy is introduced (Fig. 5b, d). As a result, the $\mathrm{TiS}_{2}$ crystal remains relatively undisturbed during the migration process. This can explain why the $\mathrm{TiS}_{2}$ coating dramatically improves the lifetime of the $\mathrm{VS}_{2}$ cathode. Through repeated charging and discharging cycles, periodic agitation to the host $\mathrm{VS}_{2}$ material can cause degradation over time. With $\mathrm{TiS}_{2}$ coating, the robust outermost layers endure much less disturbance during Li migration. As a result, the outer $\mathrm{TiS}_{2}$ is resilient to the charging/discharging cycles, while the inner $\mathrm{VS}_{2}$ layers are more protected from degradation due to the mechanical support provided by the $\mathrm{TiS}_{2}$ coating.

To extend the generality of our study, we also investigated partially intercalated systems (Supplementary Fig. 14), which contains one $\mathrm{Li}$ per unit of $\mathrm{VS}_{2}$ or $\mathrm{TiS}_{2}$. We found that $\mathrm{LiVS}_{2}$ Peierls distorts in a manner similar to what we found in $\mathrm{Li}_{2} \mathrm{VS}_{2}$. Meanwhile, the distortion in $\mathrm{LiTiS}_{2}$ is imperceptible (Supplementary Fig. 14), as it was in $\mathrm{Li}_{2} \mathrm{TiS}_{2}$. Note that the cathode likely contains regions of both $\mathrm{LiVS}_{2}$ and $\mathrm{Li}_{2} \mathrm{VS}_{2}$, resulting in an intermediate capacity as observed in the experiments. These results suggest that the distortion of Li-intercalated $\mathrm{VS}_{2}$ appears at various intercalation concentrations, and therefore occurs throughout the entire charge/discharge process. By contrast, Liintercalated $\mathrm{TiS}_{2}$ remains resilient to distortion, suggesting that the $\mathrm{TiS}_{2}$ coating can protect the inner $\mathrm{VS}_{2}$ through the complete charge-discharge cycle.

Since DFT indicates that $\mathrm{TiS}_{2}$ offers superior stability compared to $\mathrm{VS}_{2}$, then would a bulk $\mathrm{TiS}_{2}$ flake be superior to 
a

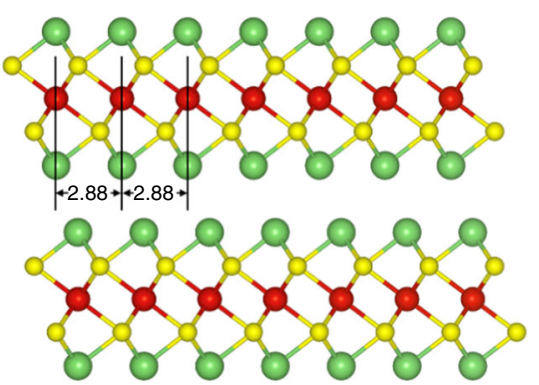

C

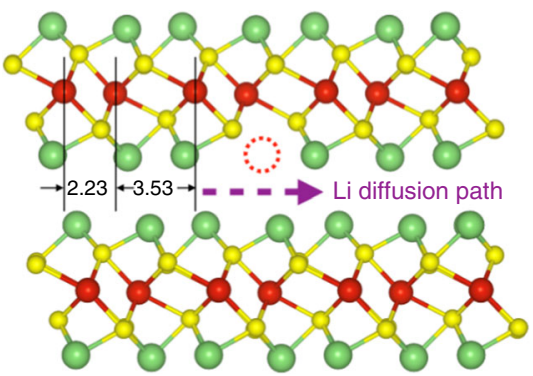

b

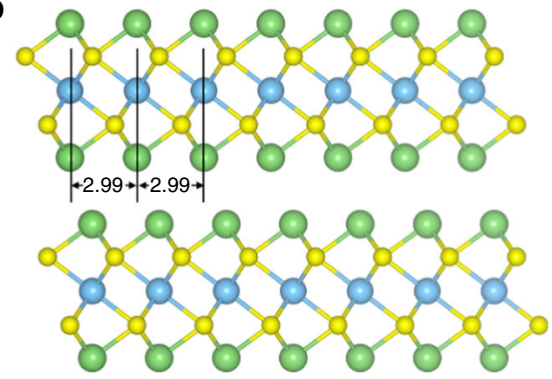

d

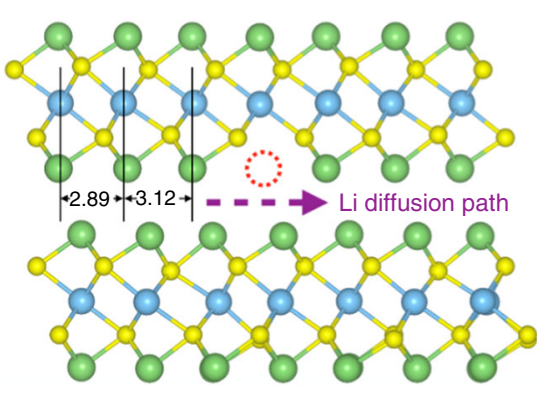

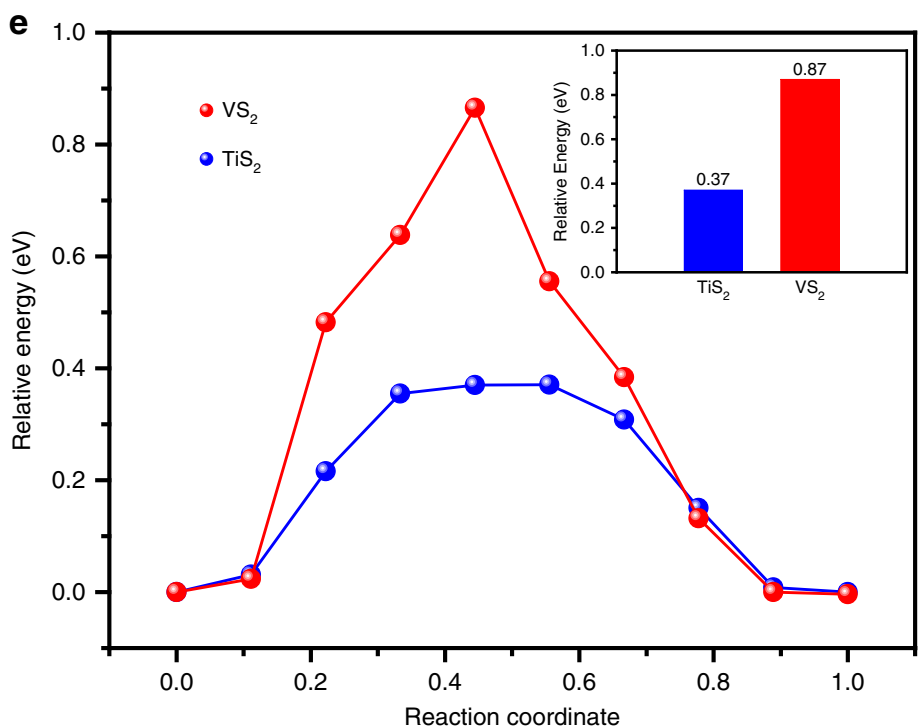

Fig. 5 DFT calculations. Fully intercalated pristine layered structures, $\mathbf{a} \mathrm{Li}_{2} \mathrm{VS} \mathrm{S}_{2}$ and $\mathbf{b} \mathrm{Li}_{2} \mathrm{TiS}_{2}$. Here, the yellow and green balls symbolize sulfur and lithium atoms, respectively. Vanadium atoms are red and titanium atoms are blue. Lithium diffusion in these systems requires that a neighboring lithium site is vacant. The corresponding intercalated structures with $\mathrm{Li}$ vacancies, marked with dashed red circles are shown for $\mathbf{c} \mathrm{Li}_{2} \mathrm{VS} \mathrm{S}_{2}$ and $\mathbf{d} \mathrm{Li}_{2} \mathrm{TiS}_{2}$. Lithium diffusion paths are indicated by purple arrows. Notice that the even spacing of $2.88 \AA$ between vanadium atoms in fully intercalated $\mathrm{Li}_{2} \mathrm{VS} \mathrm{S}_{2}$ distort to 2.23 and $3.53 \AA$ when a lithium vacancy is introduced. The distortion is much smaller in $\mathrm{Li}_{2} \mathrm{TiS}_{2}$, for which the distances between titanium atoms distort from $2.99 \AA$ to $2.89 \AA$ and $3.12 \AA$. e Energy profile along the lithium diffusion path in the $\mathrm{VS}_{2}$ and $\mathrm{TiS}_{2}$ (inset indicates the energy barriers for lithium migration). Reaction coordinates 0 and 1 correspond to the beginning and end of the lithium migration paths, which are equilibrium systems, while noninteger reaction coordinates in-between denote the fraction of the lithium migration path that has been traversed. DFT density functional theory

$\mathrm{VS}_{2}-\mathrm{TiS}_{2}$ ? While $\mathrm{TiS}_{2}$ is a metal, it is $\sim 4.5$ times less conductive than $\mathrm{VS}_{2}$. Reported electrical conductivity value for $\mathrm{VS}_{2}{ }^{18}$ is $\sim 3000 \mathrm{~S} \mathrm{~cm}^{-1}$ compared to $\sim 676 \mathrm{~S} \mathrm{~cm}^{-1}$ for $\mathrm{TiS}_{2}{ }^{31}$. For $\sim 2.5 \mathrm{~nm}$ $\mathrm{TiS}_{2}$ coating, this is not a significant limitation (Supplementary Fig. 7), but for thicker $\mathrm{TiS}_{2}$ flakes, the lower conductivity can limit performance, especially for fast charging and high power applications. For this reason, the $\mathrm{VS}_{2}-\mathrm{TiS}_{2}$ electrode is preferred to only $\mathrm{TiS}_{2}$ or only $\mathrm{VS}_{2}$.

Lastly, we used DFT to investigate the binding strength of lithium with pure $\mathrm{VS}_{2}$ and $\mathrm{VS}_{2}$ with a coating layer of $\mathrm{TiS}_{2}$. Our calculations indicate that the binding energy of lithium to the second layer of fully charged, pure $\mathrm{VS}_{2}$ is $3.12 \mathrm{eV}$. By replacing the top layer of $\mathrm{VS}_{2}$ with $\mathrm{TiS}_{2}$, this binding energy is slightly reduced to $3.09 \mathrm{eV}$. Assuming that binding energies should result in more residual lithium trapped in the material after the recharging process, we can use these energies to estimate the ratio of lithium occupation in both materials after delithiation. The canonical distribution of statistical mechanics predicts this ratio to be: $R=e^{-\Delta E / k_{\mathrm{B}} T}$, where $\Delta E$ is the difference in formation energies, $k_{\mathrm{B}}=8.62 \times 10^{-5} \mathrm{eV} \mathrm{K}^{-1}$ is Boltzmann constant, and $T=293 \mathrm{~K}$ is the room temperature. Inserting $\Delta E=3.13-3.09=0.03 \mathrm{eV}$, we estimate that the residual lithium occupation in pure $\mathrm{VS}_{2}$ to be about three times greater than that of $\mathrm{VS}_{2}$ with the $\mathrm{TiS}_{2}$ coating. As a result, we expect that delithiation, and therefore the 
recharging of the battery, is more complete with the $\mathrm{TiS}_{2}$ coating. This result also indicates that the presence of $\mathrm{TiS}_{2}$ improves the capacity retention of the battery during charge-discharge cycles.

\section{Discussion}

To summarize, we have demonstrated a procedure to stabilize $\mathrm{VS}_{2}$ cathodes in Li-ion batteries, based on coating with $\mathrm{TiS}_{2}$. Electrochemical testing, in situ optical imaging and first principles DFT calculations indicate that the stability of the battery is drastically improved after the $\mathrm{VS}_{2}$ core is encapsulated by a thin $(\sim 2.5 \mathrm{~nm}) \mathrm{TiS}_{2}$ coating layer. SEM imaging of the $\mathrm{VS}_{2}$ electrode post cycling indicates that $\mathrm{VS}_{2}$ layers tend to delaminate (i.e., peel off) the surface of the bulk $\mathrm{VS}_{2}$ flake. This is to be expected as structural distortion due to $\mathrm{Li}$ intercalation and extraction will have the greatest negative impact on the outermost $\mathrm{VS}_{2}$ layers. These layers are the least protected and the most vulnerable. The $\mathrm{VS}_{2}$ sheets within the bulk of the flake are mechanically supported (buttressed) by neighboring sheets and are therefore far less likely to detach or separate from the flake. Therefore supporting the outermost $\mathrm{VS}_{2}$ layers close to the surface becomes critical, which is what the $\sim 2.5 \mathrm{~nm}$-thick $\mathrm{TiS}_{2}$ coating is able to accomplish. Since there is minimal lattice distortion to the $\mathrm{TiS}_{2}$ coating, the $\mathrm{TiS}_{2}$ layer remains intact on the $\mathrm{VS}_{2}$ flake. Its presence prevents the underlying $\mathrm{VS}_{2}$ layers from delaminating from the surface of the flake, in spite of the large lattice distortion and volume changes that these underlying layers will encounter on lithiation and delithiation. In this way, the presence of $\mathrm{TiS}_{2}$ at the surface preserves the structure of $\mathrm{VS}_{2}$ and prevents the delamination and break-up of the $\mathrm{VS}_{2}$ material during the lithiation - delithiation process. These findings provide new opportunity for the rational design of conductive TMD materials for building high-performance Li-ion batteries.

\section{Methods}

VS $_{\mathbf{2}}$ growth on the carbon current collector by CVD. Dual-zone APCVD was utilized for the synthesis of vanadium disulfide $\left(\mathrm{VS}_{2}\right)$ sheets on the carbon nanotube current collector. As shown in schematic Fig. 1a, the source boats containing vanadium trichloride $\left(\mathrm{VCl}_{3}\right)$ and sulfur $(\mathrm{S})$ powders were arranged within a quartz tube in the furnace tube, where $\mathrm{VCl}_{3}$ was located at the center of the furnace, while $\mathrm{S}$ was placed $\sim 25 \mathrm{~cm}$ upstream. The substrate which is about $14 \mathrm{~mm} \times 75 \mathrm{~mm} \times 0.02 \mathrm{~mm}$ $(\mathrm{W} \times \mathrm{L} \times \mathrm{H})$ faced downward on the top edge of the source boat containing $\mathrm{VCl}_{3}$. Since the ratio between vanadium and sulfur was critical to achieving the suitable stoichiometry, the evaporation of $\mathrm{VCl}_{3}$ and $\mathrm{S}$ powders were independently controlled by two temperature zones. In the optimized growth condition, a quartz boat containing $\sim 0.1 \mathrm{~g} \mathrm{VCl}_{3}$ powders (Sigma-Aldrich) was placed in the center of the first furnace zone, and a quartz boat containing $\sim 0.6 \mathrm{~g} \mathrm{~S}$ powders (Sigma-Aldrich) was positioned in the center of the second furnace zone. Both boats were semi-cylindrical cuts from a quartz tube without vertical edges along the direction of flow, which allows for more even downstream flow of the precursor materials to the substrates. Before the growth, the quartz tube was baked at $\sim 120^{\circ} \mathrm{C}$ and purged with $\sim 80 \mathrm{sccm}$ forming gas (nitrogen mixed with $\sim 5 \%$ hydrogen) for $\sim 1 \mathrm{~h}$. Then, the heating zone 1 with the $\mathrm{VCl}_{3}$ boat was heated to $\sim 750^{\circ} \mathrm{C}$ at a rate of $\sim 80^{\circ} \mathrm{C} / \mathrm{min}$. The temperature of the $\mathrm{S}$ boat during growth was $\sim 250^{\circ} \mathrm{C}$. When the $\mathrm{VCl}_{3}$ temperature reached $\sim 750{ }^{\circ} \mathrm{C}$, the gas flow was reduced to $\sim 50 \mathrm{sccm}$. After $\sim 10$-min growth of $\mathrm{VS}_{2}$ under atmospheric pressure, the flow rate was increased to $\sim 80 \mathrm{sccm}$ again and the system was naturally cooled down to room temperature over $\sim 2.5 \mathrm{~h}$.

TiS $_{2}$ ultrathin layer coating by ALD. The $\mathrm{VS}_{2}$ sample was loaded in the ALD chamber for polycrystal $\mathrm{TiS}_{2}$ coating at $\sim 400^{\circ} \mathrm{C}$. A solid-precursor-cylinder containing $\mathrm{S}$ powder was connected to the ALD system for sulfur supply, while titanium tetrachloride $\left(\mathrm{TiCl}_{4}\right)$ was used as the titanium (Ti) precursor. To maintain the high vapor pressure of both precursors, the temperature of the solid-precursor-cylinder and $\mathrm{TiCl}_{4}$ cylinder were maintained at $\sim 400^{\circ} \mathrm{C}$ and $\sim 30^{\circ} \mathrm{C}$, respectively. The base pressure of the system was $\sim 900$ mTorr by using Ar as the carrier gas $(\sim 100 \mathrm{sccm})$. The ALD growth cycle consisted of $\sim 10 \mathrm{~s} \mathrm{~S}$ pulsing $+\sim 30 \mathrm{~s} \mathrm{Ar}$ purging $+\sim 5 \mathrm{~s} \mathrm{TiCl}_{4}$ pulsing $+\sim 30 \mathrm{~s}$ Ar purging. One hundred cycles yielded $\sim 2 \mathrm{~nm}$ thick polycrystal $\mathrm{TiS}_{2}$ coating $\left(\mathrm{VS}_{2}-\mathrm{TiS}_{2}\right)$ with the deposition rate of $\sim 0.02 \mathrm{~nm} /$ cycle.

Surface and crystal structure characterizations. The structure of the materials $\left(\mathrm{VS}_{2}-\mathrm{TiS}_{2}\right.$ and $\mathrm{VS}_{2}$ ) was investigated by SEM (Carl Zeiss Supra field-emission scanning electron microscope). Energy-dispersive X-ray spectroscopy (EDS) in conjunction with SEM analysis and Raman spectroscopy measurements were conducted to obtain the surface elemental information. The Raman measurements were performed with a lab-made micro Raman spectrometer. To prevent possible oxidation of vanadium disulfide caused by laser irradiation, the samples were mounted in an optical cryostat covered by a quartz window with an internal pressure of $\sim 7 \times 10^{-7}$ Torr. The $532 \mathrm{~nm}$ laser with a spot size of $\sim 2 \mu \mathrm{m}$ and intensity of $\sim 5 \mathrm{~mW}$ (LRS-0532 DPSS, Laserglow Technologies, Canada) was irradiated on the sample through the quartz window. The reflected signal was obtained and analyzed by a high-speed spectroscopy CCD camera (iDus 420 Series, Andor Technology Ltd, UK) and imaging spectrometer (Shamrock 500i, Andor Technology Ltd, UK). The resolution of the Raman system is $\sim 0.6 \mathrm{~cm}^{-1}$. The step size used in measurements was $\sim 1.34 \mathrm{~cm}^{-1}$. All spectra were collected by integrating the signal for $\sim 60 \mathrm{~s}$. A Tecnai TF-30 transmission electron microscope (FEI, Hillsboro, OR) was used to study the crystal structure of synthesized flakes and the surface distribution of $\mathrm{TiS}_{2}$ layer. Focused ion beam (FIB) imaging was performed on an FEI Helios Nanolab 600i dual beam electron microscope. The FIB was conducted with gallium ions operating at $30 \mathrm{kV}$ and electron imaging was performed at $15 \mathrm{kV}$. XPS was carried out using Al Ka radiation $(\sim 1486 \mathrm{eV})$ in a PHI 5000 Versaprobe ${ }^{\mathrm{TM}}$ system with a hemispherical analyzer and an 8-channel detector. XRD was done in a PANalytical X'Pert Pro Diffractometer.

Electrochemical measurements. The electrochemical properties of the $\mathrm{VS}_{2}$ flakes without/with $\mathrm{TiS}_{2}$ coating as cathode materials in Li-ion batteries were evaluated by a galvanostatic charge/discharge technique. Coin cells (2032-type) were used to assemble test cells in an Ar-filled glove box (MBraun Labstar). The electrodes $\left(\mathrm{VS}_{2}\right.$, $\mathrm{VS}_{2}-\mathrm{TiS}_{2}$ ) and current collector were cut to the desired shape without binder or additional conductive additives. The mass loading of the composite was $\sim 3.5 \mathrm{mg}$ $\mathrm{cm}^{-2}$ and the capacity was normalized on the total mass of the electrodes. Metallic lithium was used as the counter/reference electrode. A total of $\sim 30 \mu \mathrm{L}$ of $\sim 1 \mathrm{M}$ lithium bis(trifluoromethanesulfonyl)imide in 1,3-dioxolane and 1,2-dimethoxyethane (1:1 by volume) with $\sim 0.1 \mathrm{~mol} \mathrm{~L}^{-1} \mathrm{LiNO}_{3}$ additive was used as the electrolyte. Charge-discharge measurements were carried out galvanostatically at various current densities over a voltage range of 1.5 to $3.5 \mathrm{~V}$ (vs. $\mathrm{Li} / \mathrm{Li}^{+}$) using an Arbin BT2000 battery testing system.

In situ optical observation. A designed transparent cell was built for in situ optical observation during the lithiation-delithiation process. For this, the $\mathrm{VS}_{2}$ flakes grown by APCVD were transferred onto an $\mathrm{SiO}_{2} / \mathrm{Si}$ substrate $\left.(\sim 300 \mathrm{~nm} \mathrm{SiO})_{2}\right)$ by simple tapping. $\mathrm{VS}_{2}$ nanoflakes on the substrate with a lateral size of $\sim 30 \mu \mathrm{m}$ were targeted by optical microscopy. Next a shadow mask with grids of $\sim 80 \mu \mathrm{m}$ were applied on the top to deposit the Au pattern by e-beam evaporation, so as to partially cover the flake. The patterned sample that acts as the cathode in the Li-ion cell was then transferred into the glove box for the device assembly. A Li anode, the patterned $\mathrm{VS}_{2}$ or $\mathrm{VS}_{2}-\mathrm{TiS}_{2}$ cathode and the liquid electrolyte were encapsulated within a transparent enclosure. The anode and cathode materials were in contact with stainless steel meshes that served as the current collectors for the battery. A cover glass was placed on top of the central region and the electrolyte was filled into this region. The visualization cell, including cut outs for the current collectors were sealed using epoxy (Supplementary Fig. 11).

Density functional theory simulation. Calculations utilized plane-wave DFT with projector augmented-wave (PAW) pseudopotentials as implemented in the Vienna ab initio Simulation Package (VASP) ${ }^{32}$. The generalized gradient approximation (GGA) was employed using the Perdew-Burke-Ernzerhof functional ${ }^{33}$, for which van der Waals interactions were considered using density functional methods of optB86 ${ }^{34,35}$ Ionic relaxation calculations used a plane-wave basis set including energies up to 550 $\mathrm{eV}$. We assume that, when fully lithiated, the bulk TMD crystals can hold two Li for each unit of $\mathrm{MS}_{2}(\mathrm{M}=\mathrm{Ti}$ or $\mathrm{V})$, with one Li bound above and one below each transition metal atom. Hence, we denote the intercalated TMD by the chemical formula $\mathrm{Li}_{2} \mathrm{MS}_{2}$. For the primitive bulk cells of $\mathrm{Li}_{2} \mathrm{VS}_{2}$ and $\mathrm{Li}_{2} \mathrm{TiS}_{2}$, the Brillouin zone was sampled with a $\Gamma$-centered Monkhorst-Pack mesh of dimensions $11 \times 11 \times 4$. Relaxation iterations persisted until all interatomic Hellmann-Feynman forces settled below $0.01 \mathrm{eV} \AA^{-1}$ for all atoms, while the self-consistent field iterations ceased when the changes in both total energy and the eigenvalues settled below $10^{-6} \mathrm{eV}$ between iterations. Calculations involving cathode surfaces included $16 \AA$ of vacuum separation to eliminate interactions between periodic adjacent cells. Larger amounts of vacuum produced nearly identical ground state energies.

During the discharging process, the intercalated Li evacuate the crystal, traveling in-plane between the $\mathrm{MS}_{2}$ layers towards the crystal's edge via successive migrations to unoccupied $\mathrm{Li}$ sites. The activation energies required for these migration were calculated using the nudged elastic band method combined with the climbing-image technique ${ }^{36}$. For these calculations, a Li vacancy is placed in an otherwise fully intercalated $4 \times 4 \times 2$ supercell, while eight intermediate images are used to describe its migration to an adjacent site.

In addition, the formation energies of dilithiation of a single layer were calculated using; $E_{\text {form }}=E_{\text {int }}-E_{\mathrm{vac}}-2 \times E_{\mathrm{Li}}$, where $E_{\mathrm{int}}, E_{\mathrm{vac}}$, and $E_{\mathrm{Li}}$ are the free energies of a fully intercalated system, a system with one layer of $\mathrm{Li}$ removed, and an isolated $\mathrm{Li}^{+}$ ion. The binding energies are then the additive inverses of the free energies.

Lastly, to extend the generality of our study, we investigated lithiation and delithiation in partially intercalated TMDs, which contains one Li per unit of MS 
and is denoted as $\mathrm{LiMS}_{2}$. We removed one $\mathrm{Li}$ from an otherwise pristine $4 \times 4 \times 2$ $\mathrm{LiMS}_{2}$, and allowed the system to relax, respecting the same convergence criteria as described above.

\section{Data availability}

All relevant data are available from the corresponding author upon request.

Received: 20 September 2018 Accepted: 4 March 2019

Published online: 16 April 2019

\section{References}

1. Duan, X. et al. Lateral epitaxial growth of two-dimensional layered semiconductor heterojunctions. Nat. Nanotech. 9, 1024-1030 (2014).

2. Chhowalla, M. et al. The chemistry of two-dimensional layered transition metal dichalcogenide nanosheets. Nat. Chem. 5, 263-275 (2013).

3. Stephenson, T., Li, Z., Olsen, B. \& Mitlin, D. Lithium ion battery applications of molybdenum disulfide $\left(\mathrm{MoS}_{2}\right)$ nanocomposites. Energy Environ. Sci. 7, 209-231 (2014).

4. Chang, K. \& Chen, W. l-Cysteine-assisted synthesis of layered $\mathrm{MoS}_{2}$ /graphene composites with excellent electrochemical performances for lithium ion batteries. ACS Nano 5, 4720-4728 (2011).

5. Gao, J. et al. Vertically oriented arrays of $\mathrm{ReS}_{2}$ nanosheets for electrochemical energy storage and electrocatalysis. Nano Lett. 16, 3780-3787 (2016).

6. Feng, J. et al. Metallic few-layered $\mathrm{VS}_{2}$ ultrathin nanosheets: high twodimensional conductivity for in-plane supercapacitors. J. Am. Chem. Soc. 133, 17832-17838 (2011).

7. Fang, W. et al. Facile hydrothermal synthesis of $\mathrm{VS}_{2} /$ graphene nanocomposites with superior high-rate capability as lithium-ion battery cathodes. ACS Appl. Mater. Interfaces 7, 13044-13052 (2015).

8. Wang, D. et al. Two-dimensional $\mathrm{VS}_{2}$ monolayers as potential anode materials for lithium-ion batteries and beyond: first-principles calculations. J. Mater. Chem. A 5, 21370-21377 (2017).

9. Mikhaleva, N., Visotin, M., Kuzubov, A. \& Popov, Z. I. VS 2 /graphene heterostructures as promising anode material for Li-ion batteries. J. Phys. Chem. C 121, 24179-24184 (2017).

10. Murphy, D., Carides, J., Di Salvo, F., Cros, C. \& Waszczak, J. V. Cathodes for nonaqueous lithium batteries based on $\mathrm{VS}_{2}$. Mater. Res. Bull. 12, 825-830 (1977).

11. Jing, Y., Zhou, Z., Cabrera, C. R. \& Chen, Z. Metallic $\mathrm{VS}_{2}$ monolayer: promising 2D anode material for lithium ion batteries. J. Phys. Chem. C 117, 25409-25413 (2013)

12. Li, X. et al. Significant impact on cathode performance of lithium-ion batteries by precisely controlled metal oxide nanocoatings via atomic layer deposition. J. Power Sources 247, 57-69 (2014).

13. Sun, Y.-K. et al. The role of $\mathrm{AlF}_{3}$ coatings in improving electrochemical cycling of Li-enriched nickel-manganese oxide electrodes for Li-ion batteries. Adv. Mater. 24, 1192-1196 (2012).

14. Kohandehghan, A., Kalisvaart, P., Cui, K., Memarzadeh, Kupsta,M. \& Mitlin, D. Silicon nanowire lithium-ion battery anodes with ALD deposited TiN coatings demonstrate a major improvement in cycling performance. J. Mater. Chem. A 1, 12850-12861 (2013).

15. Kim, J. W. et al. Surface chemistry of LiNi0.5Mn1.5O4 particles coated by $\mathrm{Al}_{2} \mathrm{O}_{3}$ using atomic layer deposition for lithium-ion batteries. J. Power Sources 274, 1254-1262 (2015).

16. Yuan, J. et al. Facile synthesis of single crystal vanadium disulfide nanosheets by chemical vapor deposition for efficient hydrogen evolution reaction. $A d v$. Mater. 27, 5605-5609 (2015).

17. Bonaccorso, F., Sun, Z., Hasan, T. \& Ferrari, A. C. Graphene photonics and optoelectronics. Nat. Photonics 4, 611-622 (2010).

18. Ji, Q. et al. Metallic vanadium disulfide nanosheets as a platform material for multifunctional electrode applications. Nano Lett. 17, 4908-4916 (2017).

19. Sourisseau, C., Cavagnat, R., Fouassier, M., Tirado, J. L. \& Morales, J. Raman study and lattice dynamics calculations of misfit layered compounds: (PbS) $1.18 \mathrm{TiS}_{2}$ and $(\mathrm{PbS}) 1.12 \mathrm{VS}_{2}$. J. Mol. Struct. 348, 107-110 (1995)

20. Seh, Z. W. et al. Two-dimensional layered transition metal disulphides for effective encapsulation of high-capacity lithium sulphide cathodes. Nat. Commun. 5, 5017 (2014).

21. Yuwen, L. et al. Rapid preparation of single-layer transition metal dichalcogenide nanosheets via ultrasonication enhanced lithium intercalation. Chem. Commun. 52, 529-532 (2016).

22. Suri, D. et al. A study of electron and thermal transport in layered titanium disulphide single crystals. J. Phys. Condens. Matter 29, 485708 (2017).

23. Liang, H. et al. Solution growth of vertical $\mathrm{VS}_{2}$ nanoplate arrays for electrocatalytic hydrogen evolution. Chem. Mater. 28, 5587-5591 (2016).
24. Liu, J.-Z. \& Guo, P.-F. VS 2 nanosheets: a potential anode material for Li-ion batteries. J. Inorg. Mater. 30, 1339-1344 (2015).

25. Masikhwa, T. M. et al. Asymmetric supercapacitor based on $\mathrm{VS}_{2}$ nanosheets and activated carbon materials. Rsc Adv. 6, 38990-39000 (2016).

26. Sun, R. et al. Novel layer-by-layer stacked $\mathrm{VS}_{2}$ nanosheets with intercalation pseudocapacitance for high-rate sodium ion charge storage. Nano Energy 35 396-404 (2017).

27. Rantho, M. N. et al. Asymmetric supercapacitor based on vanadium disulfide nanosheets as a cathode and carbonized iron cations adsorbed onto polyaniline as an anode. Electrochim. Acta 260, 11-23 (2018).

28. Kim, G., Gim, S., Cho, S., Koratkar, N. \& Oh, I.-K. Wetting-transparent graphene films for hydrophobic water-harvesting surfaces. Adv. Mater. 26 , 5166-5172 (2014)

29. Hadjiev, V. et al. Raman microscopy of residual strains in carbon nanotube/ epoxy composites. Carbon N.Y. 48, 1750-1756 (2010).

30. Guan, D., Jeevarajan, J. \& Wang, Y. Enhanced cycleability of $\mathrm{LiMn}_{2} \mathrm{O}_{4}$ cathodes by atomic layer deposition of nanosized-thin $\mathrm{Al}_{2} \mathrm{O}_{3}$ coatings. Nanoscale 3, 1465-1469 (2011).

31. Lin, C. et al. Hydrogen-incorporated $\mathrm{TiS}_{2}$ ultrathin nanosheets with ultrahigh conductivity for stamp-transferrable electrodes. J. Am. Chem. Soc. 135 , 5144-5151 (2013).

32. Kresse, G. \& Furthmüller, J. Efficiency of ab-initio total energy calculations for metals and semiconductors using a plane-wave basis set. Comput. Mater. Sci. 6, 15-50 (1996)

33. Perdew, J. P., Burke, K. \& Ernzerhof, M. Generalized gradient approximation made simple. Phys. Rev. Lett. 77, 3865-3868 (1996).

34. Klimeš, J., Bowler, D. R. \& Michaelides, A. Van der waals density functionals applied to solids. Phys. Rev. B 83, 195131 (2011).

35. Jiří, K., David, R. B. \& Angelos, M. Chemical accuracy for the van der waals density functional. J. Phys. Condens. Matter 22, 022201 (2010).

36. Henkelman, G., Uberuaga, B. P. \& Jónsson, H. A climbing image nudged elastic band method for finding saddle points and minimum energy paths. $J$ Chem. Phys. 113, 9901-9904 (2000).

37. Zhang, Y. et al. Improving the performance of a $\mathrm{LiFePO}_{4}$ cathode based on electrochemically cleaved graphite oxides with high hydrophilicity and good conductivity. J. Mater. Chem. A 1, 7933-7941 (2013).

38. Lung-Hao Hu, B., Wu, F.-Y., Lin, C.-T., Khlobystov, A. N. \& Li, L.-J. Graphene-modified $\mathrm{LiFePO}_{4}$ cathode for lithium ion battery beyond theoretical capacity. Nat. Commun. 4, 1687 (2013).

39. Delaporte, N. et al. Increasing the affinity between carbon-coated $\mathrm{LiFePO}_{4} / \mathrm{C}$ electrodes and conventional organic electrolyte by spontaneous grafting of a benzene-trifluoromethylsulfonimide moiety. ACS Appl. Mater. Interfaces 7, 18519-18529 (2015)

40. $\mathrm{Fu}, \mathrm{X}$. et al. Low-temperature synthesis of $\mathrm{LiMnPO}_{4} / \mathrm{RGO}$ cathode material with excellent voltage platform and cycle performance. Electrochim. Acta 225, 272-282 (2017).

41. Liu, L. et al. Improved rate and cycle performance of nano-sized $5 \mathrm{LiFePO} \cdot \mathrm{Li}_{3} \mathrm{~V}_{2}\left(\mathrm{PO}_{4}\right) 3 / \mathrm{C}$ via high-energy ball milling assisted carbothermal reduction. J. Alloy. Comp. 719, 281-287 (2017).

42. Liang, $\mathrm{S}$. et al. Uniform $8 \mathrm{LiFePO} \cdot \mathrm{Li}_{3} \mathrm{~V}_{2}\left(\mathrm{PO}_{4}\right) 3 / \mathrm{C}$ nanoflakes for highperformance Li-ion batteries. Nano Energy 22, 48-58 (2016).

43. Wang, $\mathrm{X}$. et al. Graphene-decorated carbon-coated $\mathrm{LiFePO}_{4}$ nanospheres as a high-performance cathode material for lithium-ion batteries. Carbon N.Y. 127, 149-157 (2018).

44. Choi, A. et al. Site-selective in situ electrochemical doping for Mn-rich layered oxide cathode materials in lithium-ion batteries. Adv. Energy Mater. 8, 1702514 (2018).

45. Wu, B. et al. Morphology controllable synthesis and electrochemical performance of $\mathrm{LiCoO}_{2}$ for lithium-ion batteries. Electrochim. Acta 209, 315-322 (2016)

46. Zheng, F. et al. Nanoscale surface modification of lithium-rich layered-oxide composite cathodes for suppressing voltage fade. Angew. Chem. Int. Ed. 54, 13058-13062 (2015)

47. Wang, Y., Yang, Z., Qian, Y., Gu, L. \& Zhou, H. New insights into improving rate performance of lithium-rich cathode material. Adv. Mater. 27, 3915-3920 (2015).

48. Zhang, S. J. et al. Sodium-alginate-based binders for lithium-rich cathode materials in lithium-ion batteries to suppress voltage and capacity fading. ChemElectroChem 5, 1321-1329 (2018).

49. Guo, H. Abundant nanoscale defects to eliminate voltage decay in Li-rich cathode materials. Energy Storage Mater. 16, 220-227 (2019).

\section{Acknowledgements}

This work was supported by the USA National Science Foundation (award number 1608171). N.K. also acknowledges funding support from the John A. Clark and Edward T. Crossan endowed chair professorship at the Rensselaer Polytechnic Institute (RPI). S.-F.S. acknowledges support from the AFOSR through award number FA9550-18-1 0312. G.-C.W. acknowledges support from the Travelstead chair fund at RPI and the NYSTAR Focus Center (award number C150117). J.S. was supported by the AFOSR 
under award number FA9550-18-1-0116. Z.C. was supported by the USA National Science Foundation under award number 1706815.

\section{Author contributions}

L.L. designed and conducted the battery test. Z.L., A.L., Y.X. and G.-C.W. carried out CVD growth of the TMD materials. A.Y. and V.M. performed the theoretical calculations. C.S. performed the TEM analysis. Z.L., Z.C., and J.S. performed the ALD. L.L., Z.L., T.W., Y.C., and S.-F.S. carried out the in situ optical observation. P.H. carried out XPS characterization. S.F.B. carried out FIB/SEM imaging. L.L., Z.L., A.Y., and N.K. wrote the manuscript. N.K. supervised and directed the research project. N.K. also contributed to writing the manuscript and analyzing the data. All authors discussed the results and commented on the manuscript.

\section{Additional information}

Supplementary Information accompanies this paper at https://doi.org/10.1038/s41467019-09400-w.

Competing interests: The authors declare no competing interests.

Reprints and permission information is available online at http://npg.nature.com/ reprintsandpermissions/
Journal peer review information: Nature Communications thanks the anonymous reviewer(s) for their contribution to the peer review of this work.

Publisher's note: Springer Nature remains neutral with regard to jurisdictional claims in published maps and institutional affiliations.

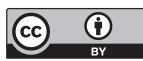

Open Access This article is licensed under a Creative Commons Attribution 4.0 International License, which permits use, sharing, adaptation, distribution and reproduction in any medium or format, as long as you give appropriate credit to the original author(s) and the source, provide a link to the Creative Commons license, and indicate if changes were made. The images or other third party material in this article are included in the article's Creative Commons license, unless indicated otherwise in a credit line to the material. If material is not included in the article's Creative Commons license and your intended use is not permitted by statutory regulation or exceeds the permitted use, you will need to obtain permission directly from the copyright holder. To view a copy of this license, visit http://creativecommons.org/ licenses/by/4.0/.

(C) The Author(s) 2019 